\title{
Effect of Welding Speed and Tool Pin Geometry on Impact Strength in Friction Stir Welding of Aluminium 6101 T6 Alloy
}

\author{
Rajbir Singh ${ }^{1}$, Sanjeev Kumar ${ }^{2}$ and Preet Kanwal Singh ${ }^{3}$ \\ ${ }^{1}$ Research scholar, Mechanical Department, BCET Gurdaspur, India. \\ ${ }^{2}$ Associate professor, Mechanical Department, BCET Gurdaspur , India. \\ ${ }^{3}$ Assistant professor, Mechanical Department, BCET Gurdaspur , India.
}

\begin{abstract}
Friction stir welding (FSW) process is a solid state joining method in which the material that is being welded does not melt and recast. This process uses a non-consumable tool to generate frictional heat in the abutting surfaces. The welding parameters play a major role in deciding the joint characteristics. In this investigation the effect of welding speed and tool pin geometry in friction stir welds of Aluminium alloy was studied. The welded joints were made of Aluminium alloy AA 6101 T6 strips of 6mm thickness with different tool pin profile (Cylindrical, Taper cylindrical, Square and Taper Square). All the welding operations were done at the room temperature. Charpy tests were carried out to find the impact strength. From this investigation it is found that strength is superior with taper square tool pin profile than cylindrical, taper cylindrical and square tool pin profile. The pieces weld at rotational speed of 1200 r.p.m and welding speed of $70 \mathrm{~mm} / \mathrm{min}$ using taper square tool have higher strength.
\end{abstract}

\section{Introduction}

The usage of aluminium alloys in automotive and aerospace applications is ever increasing due to their light weight and cast ability. It is necessary to weld aluminium castings to themselves or to wrought alloys for various applications. These alloys are not easily weldable by conventional fusion welding technique because the quality of the welded joint is deteriorated due to the presence of porosity, hot cracking and distortion. Friction stir welding (FSW) process is an emerging solid state joining process in which the material that is being welded does not melt and recast [1].The principle of FSW process is quiet simple. It makes the use of nonconsumable tool which consists of a shoulder and a pin [2]. The pin of the rotary tool is plunged into the plates being welded till shoulder makes firm contact and then moved forward along the weld line. The frictional heat generated by the rotary tool heats and softens the material. The softened material underneath the shoulder is subjected to extrusion by the rotary and traverse movement of the tool; is transported from the advancing side to the retreating side where it is consolidated into a monolithic joint [3]. FSW creates the weld joint without bulk melting. In addition, the extensive thermo mechanical deformation induces dynamic recrystallization and recovery that refine the microstructure of the stir region. Therefore, welds made by FSW are shown to have much improved mechanical properties than the corresponding fusion welds. Since,
FSW is a solid state process and the material under the rotating action of non-consumable tool has to be stirred properly to get good, defect free welds [4]. Defect-free welds with good mechanical properties have been made in a variety of aluminium alloys, even those previously thought to be non weldable [5]. When alloys are friction stir welded, phase transformations that occur during the cooling cycle of the weld are of a solid state type. Due to the absence of parent metal melting, the FSW process is observed to offer several advantages over fusion welding processes [6]. During the welding process, frictional heat associated with the thermal cycle varies in the transverse direction of the weld. The maximum temperature is observed in the FSW zone, which causes an alteration in the precipitate distribution present in the base material and also due to stirring of the plasticized material. These changes in the heat and temperature distribution in the welding process alter the strength and ductility of the joints [7].

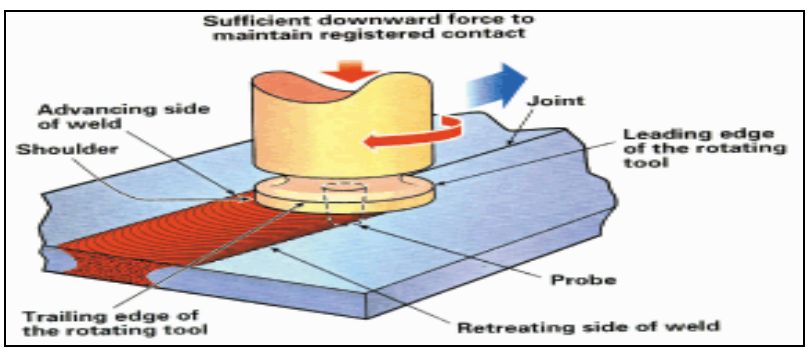

Figure 1. FSW Process

\footnotetext{
${ }^{1}$ Corresponding author: rajbir239@gmail.com
} 
The pin/shoulder geometry of the tool is responsible for homogeneous microstructure, uniform joint properties and governs process forces. Whorl and MX Triflute tool geometries reduce welding forces because of increased heat generation and lower displacement volumes of the softened materials [8]. Rotary speed of tool determines the amount of heat produced per unit time, stirring and mixing of the workpiece material around the pin [9]. Welding speed or tool traverse speed governs the maximum temperature generated during welding and the length of time the material is subjected to the welding [10]. The translation of the tool transports the stirred material from the front to the back of the pin to complete the welding [11]. High welding speed will make friction stir welded joints cheaper due to high productivity. However, too high welding speed at constant rotary speed results in the formation of void beneath the top surface of weld or on the advancing side at the edge of weld nugget. The size of the wormhole defects increases with the increase of welding speed [12]. Therefore, this present study aims to experimentally examine the effect of varying welding speed on impact strength of friction stir welded joints of AA6101 aluminum alloy.

\section{Experimental work}

The extruded plates of AA6101 of $6 \mathrm{~mm}$ thick in T6 condition were used as the base material for the present experimental study. The plates were cut to the required dimensions $(300 \times 150 \mathrm{~mm})$ by power hacksaw cutting and grinding. Four tools (Cylindrical, Taper cylindrical, Square and Taper square) were prepared having different tool pin geometry. Tool having cylindrical shaped pin and tapered cylindrical pin were prepared using Lathe machine while square and tapered square pin were prepared on Milling machine. The shoulder diameter of the tool is $18 \mathrm{~mm}$ and diameter of pin is $6 \mathrm{~mm}$. The length of the pin should be slightly less than thickness of the work piece. The thickness of work piece is $6 \mathrm{~mm}$ and pin length is $5.90 \mathrm{~mm}$. A square butt joint configuration was prepared to fabricate FSW joints. The initial joint configuration was obtained by securing the plates in position using mechanical clamps. The direction of welding was normal to the rolling direction. A single pass welding procedure was used to fabricate the joints.Non consumable tools made of high carbon high chromium steel were used to fabricate the joints. The chemical composition of the base metal was checked at IMTT Batala and the composition of various elements is shown in Table1.

Table 1. Chemical Composition of AA 6101 T6.

\begin{tabular}{|c|c|}
\hline Element & Percentage \\
\hline $\mathrm{Al}$ & $97.6 \mathrm{~min}$ \\
\hline $\mathrm{Si}$ & $0.60 \mathrm{max}$ \\
\hline $\mathrm{Fe}$ & $0.35 \max$ \\
\hline
\end{tabular}

\begin{tabular}{|c|c|}
\hline $\mathrm{Cu}$ & 0.10 max \\
\hline $\mathrm{Mn}$ & $0.10 \max$ \\
\hline $\mathrm{Mg}$ & $0.90 \max$ \\
\hline $\mathrm{Cr}$ & $0.10 \max$ \\
\hline $\mathrm{Zn}$ & $0.10 \max$ \\
\hline $\mathrm{Ti}$ & $0.10 \max$ \\
\hline Others & $0.15 \max$ \\
\hline
\end{tabular}

A Vertical Milling machine, HAAS Super VF2 (12000 rpm) available with R \& D centre, Ludhiana was used to fabricate the joints. Joints were fabricated at constant Rotational speed of 1100 r.p.m. and translation speed was taken as $40 \mathrm{~mm} / \mathrm{min}, \quad 55 \mathrm{~mm} / \mathrm{min}, \quad 70 \mathrm{~mm} / \mathrm{min}$, and $85 \mathrm{~mm} / \mathrm{min}$ respectively. Four joints were fabricated by using each tool. The process parameters and their levels and tool dimensions are presented in Table 2.

Table 2. FSW process parameters

\begin{tabular}{|c|c|}
\hline Process parameters & Values \\
\hline Tool rotation speed (rpm) & 1100 \\
\hline Welding speed (mm/min) & $40,55,70,85$ \\
\hline Pin Length (mm) & 5.90 \\
\hline Tool shoulder Diameter (mm) & 18 \\
\hline Pin diameter (mm) & 6 \\
\hline D/d ratio of tool & 3 \\
\hline Tool pin geometry & Cylindrical \\
\hline Tool material & High carbon steel \\
\hline
\end{tabular}

The welded joints were sliced using band saw and then machined to the required dimensions to prepare specimens. American Society for Testing of Materials (ASTM) guidelines were followed for preparing the test specimens. Charpy test was performed to find the impact strength of various specimens. Figure 2 shows the starting stage of Friction stir welding process and Figure 3 shows the welded Specimen 


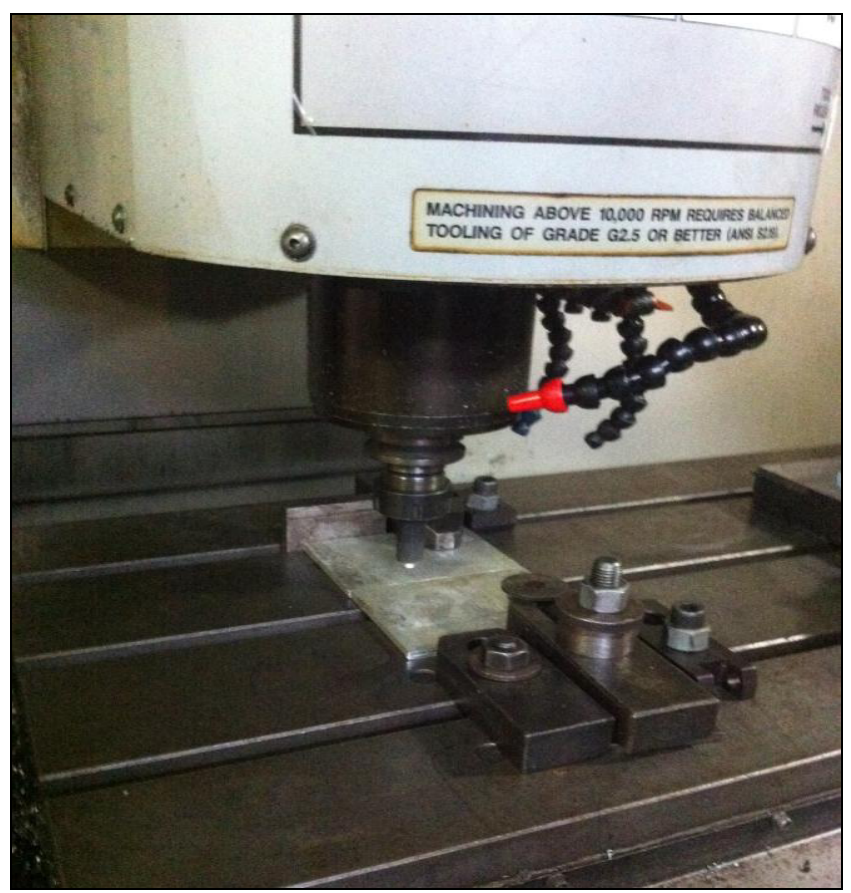

Figure 2. Starting Stage of FSW Process

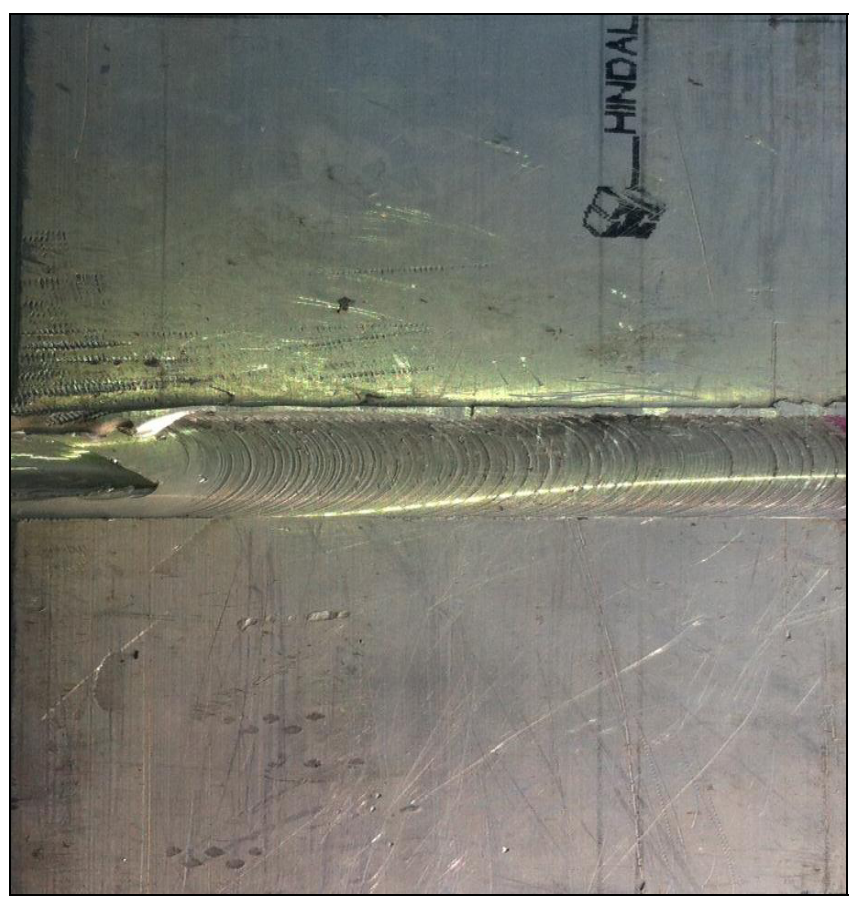

Figure 3. Welded Specimen at $1100 \mathrm{rpm}, 70 \mathrm{~mm} / \mathrm{min}$

\section{Results and discussion}

Impact strength of friction stir welded joints was measured by performing Charpy tests on transverse tensile samples containing weld nugget zone at the center. Table 3 represents the impact strength of friction stir welded joints of AA 6101T6 aluminum alloy, produced using different welding speed and various tool pin shape.

It is evident from Table 3 that impact strength of friction stir welds of AA $6101 \mathrm{~T} 6$ is inferior to base material. The joint fabricated by Taper square tool shows superior impact strength as compared to all other joints while the joints fabricated by cylindrical pin profiled tool shows inferior strength as compared to all other joints. At constant rotary speed of $1100 \mathrm{rpm}$, increase in welding speed from 40 to $70 \mathrm{~mm} / \mathrm{min}$ increases the impact strength linearly from $31 \mathrm{~J}$ to $34 \mathrm{~J}$ and then decreases to $32 \mathrm{~J}$ at welding speed of $85 \mathrm{~mm} / \mathrm{min}$ for a cylindrical pin profiled tool (Figure. 2). The maximum impact strength of weld joint was $34 \mathrm{~J}$ for cylindrical pin profiled tool. The impact strength of taper cylindrical pin profiled tool was better as compared to cylindrical pin profiled tool. The impact strength increases from $33 \mathrm{~J}$ to $38 \mathrm{~J}$ as welding speed increases from $40 \mathrm{~mm} / \mathrm{min}$ to $85 \mathrm{~mm} / \mathrm{min}$. the impact strength of square pin profiled tool is superior than cylindrical and taper cylindrical pin but is inferior to Taper square pin profiled tool. The impact strength increases from $41 \mathrm{~J}$ to $48 \mathrm{~J}$ as welding speed increases from $40 \mathrm{~mm} / \mathrm{min}$ to $70 \mathrm{~mm} / \mathrm{min}$ for a taper square pin profiled tool and then decreases to $40 \mathrm{~J}$ at welding speed of $85 \mathrm{~mm} / \mathrm{min}$. The impact strength is maximum for a Taper square pin profiled tool at welding speed of $85 \mathrm{~mm} / \mathrm{min}$. The welding speed influences the heat input per unit length of weld which controls the degree of softening and flowability of plasticized material. At lower welding speed the amount of heat supplied to the deforming material in weld area is greater and therefore wider is the softened area around the stirring tool leading to more improved metal flow and more effective bonding in the weld. This improved material flow and effective bonding leads to more homogeneity of weld nugget which results in superior impact strength of welded joints having higher heat input per unit length. With further increase in welding speed, the impact

strength of friction stir welded joints decreases and attributed towards formation of voids due to poor consolidation of weld interface at higher welding speed hence low heat input per unit weld length.

Table 3. Impact Strength of Fabricated Joints.

\begin{tabular}{|c|c|c|c|}
\hline $\begin{array}{c}\text { Sample } \\
\text { No. }\end{array}$ & $\begin{array}{c}\text { Welding } \\
\text { Speed }\end{array}$ & $\begin{array}{c}\text { Shape of } \\
\text { Tool }\end{array}$ & $\begin{array}{c}\text { Impact } \\
\text { Strength }\end{array}$ \\
\hline 1 & 40 & Cylindrical & 31 \\
\hline 2 & 55 & Cylindrical & 33 \\
\hline 3 & 70 & Cylindrical & 34 \\
\hline 4 & 85 & Cylindrical & 32 \\
\hline 5 & 40 & $\begin{array}{c}\text { Taper } \\
\text { Cylinder }\end{array}$ & 33 \\
\hline 6 & 55 & $\begin{array}{c}\text { Taper } \\
\text { Cylinder }\end{array}$ & 35 \\
\hline 7 & 70 & $\begin{array}{c}\text { Taper } \\
\text { Cylinder }\end{array}$ & 36 \\
\hline 8 & 85 & $\begin{array}{c}\text { Taper } \\
\text { Cylinder }\end{array}$ & 38 \\
\hline 9 & 40 & Square & 34 \\
\hline 10 & 55 & Square & 36 \\
\hline 11 & 70 & Square & 39 \\
\hline
\end{tabular}




\begin{tabular}{|c|c|c|c|}
\hline 12 & 85 & Square & 35 \\
\hline 13 & 40 & $\begin{array}{c}\text { Taper } \\
\text { Square }\end{array}$ & 41 \\
\hline 14 & 55 & $\begin{array}{c}\text { Taper } \\
\text { Square }\end{array}$ & 42 \\
\hline 15 & 70 & $\begin{array}{c}\text { Taper } \\
\text { Square }\end{array}$ & 48 \\
\hline 16 & 85 & $\begin{array}{c}\text { Taper } \\
\text { Square }\end{array}$ & 40 \\
\hline
\end{tabular}

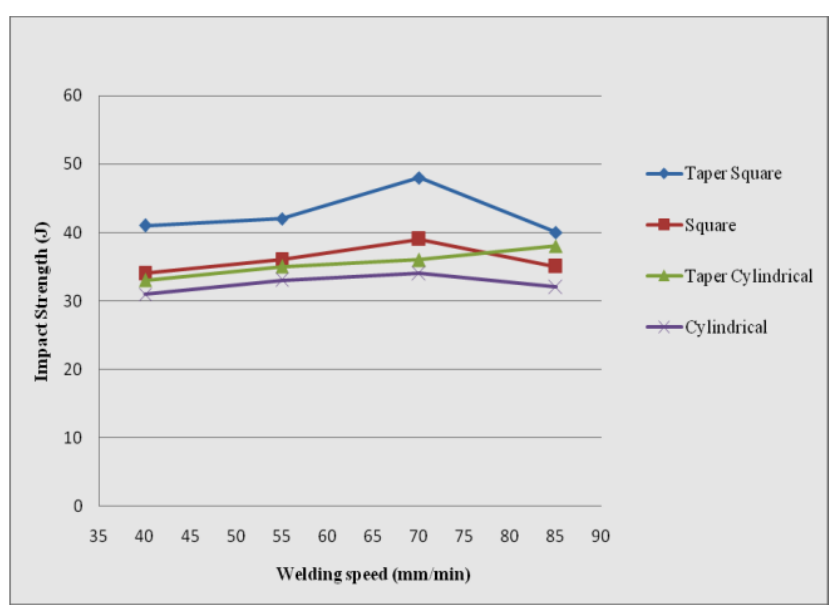

Figure 4. Effect of Welding Speed and Pin profile on Impact Strength

Pin profile plays an important role in material flow and in turn regulates the welding speed of Friction stir welding process.

Pin profiles with flat faces (square and taper square) are associated with eccentricity. This eccentricity allows incompressible material to pass around the pin profile. Eccentricity of the rotating object is related to dynamic orbit due to eccentricity. The relationship between the static volume and dynamic volume decides the path for the flow of plasticized material from the leading edge to the trailing edge of the rotating tool. This ratio is highest for taper square tool followed by square, taper cylindrical and cylindrical pin profiled tool. In addition, the taper square and square pin profiled tool produce a pulsating stirring action in flowing material due to flat faces. There is no such pulsating action in case of cylindrical and taper cylindrical pin profiled tool. The highest number of pulsating action experienced in stir zone of Taper Square pin profiled tool produces fine grains and in turn yields highest impact strength.

\section{Conclusions}

In this investigation an attempt has been made to study the effect of welding speed on the formation of friction stir processing zone in AA 6101T6 aluminium alloy. From this investigation, the following important conclusions are derived:

(i) Friction stir welding technique can be used to produce defect free weld of AA 6101T6.

(ii) Of the four pin profiles used in this investigation to fabricate the joints, taper square pin profiled tool gives better strength as compared to cylindrical, taper cylindrical and square pin profiled tool. (iii) The tool pin profile and welding speed have influence on impact strength of friction stir welding joints. The impact strength of the joints increases with increase in welding speed up to a certain limit and then decreases. Of the various joints fabricated in this investigation, the joint fabricated at rotational speed of $1100 \mathrm{rpm}$ and welding speed of $70 \mathrm{~mm} / \mathrm{min}$ using taper square pin profiled tool has highest impact strength.

\section{References}

1. W. M. Thomas, E. D. Nicholas, J. C. Needham, M. Murch, G. P. Templesmith, C. J. Dawes, G.B. Patent Application No. 9125978.8 (December 1991).

2. A. P. Reynolds, "Visualization of material flow in autogenous friction stir welds", Sci Technol Weld Joining 2000;5:120

3. K. Colligan, "Material flow behavior during friction welding of aluminum," Weld J 1999:229s-37s.

4. Y. S. Sato, H. Kokawa, K.. Ikeda, M. Enomoto, S. Jogan, and T. Hashimoto, "Microtexture in the friction-stir weld of an aluminum alloy", Metall Mater Trans A2001; 32A:941-8.

5. W. M. Zeng, H. L. Wu and J. Zhang, "Effect of tool wear on microstructure, mechanical properties and acoustic emission of friction stir welded $6061 \mathrm{Al}$ alloys", Acta Metall Sinica 2006; 19(1):9-19.

6. O. V. Flores, "Micro structural issues in a friction stir welded aluminium alloy", Scripts Mater 1998; 38(5):703-8.

7. G. Ipekoglu \& S. Erim and G. Cam (2013) "Effects of temper condition and post weld heat treatment on the microstructure and mechanical properties of friction stir butt-welded AA7075 Al alloy plates" International Journal Advance Manufacturing Technology (2013)

8. W. M. Thomas, E. D. Nicholas and S. D. Smith, Friction stir welding - Tool developments. In: S. K. Das, J. G. Kaufman, T. J. Lienert, editors. Aluminium 2001 proceedings of the TMS 2001 aluminum automotive and joining session, TMS;

9. M. Peel, A. Steuwer, M. Preuss, and P. J. Withers, "Microstructure, mechanical properties and residual stresses as a function of welding speed in AA5083 friction stir welds", Acta Materilia 2003;51(16):4791-801.

10. H. J. Liu, H. Fuji, M. Maeda and K. Nogi, "Mechanical properties of friction welded joints of 1050-H24 aluminum alloy", Sci Technol Weld Joining 2003; 8(6):450-4.2001. p. 213-24.

11. R. Nandan, D. Roy, H. K. D. H Bhadeshia, "Recent advances in friction stir welding - Process, weldment structure and properties", Progress Mater Sci 2008; 53:980-1023.

12. R. Crawford, G. E. Cook, A. M. Strauss, D. A. Hartman, and M. A. Stremler, "Experimental defect analysis and force prediction simulation of high weld pitch friction stir welding", Sci Technol Weld Joining 2006;11(6):657-65. 